\title{
Projeto Cuidando de Quem Cuida - Um Relato de Experiência
}

Project Caring for Carers: An Experience Report

\section{Resumo}

Os princípios de uma alimentação saudável são essenciais às grandes demandas nutricionais da gestação e dos eventos a ela relacionados, como a lactação. Sendo assim, é notório que o empoderamento das gestantes sobre uma alimentação equilibrada e rica em nutrientes se faz necessário, visto que a nutrição é um dos pilares mais importantes para a saúde do binômio mãe-filho. Desse modo, a realização deste trabalho teve por objetivo realizar estratégias educativas com participantes do grupo de gestantes e gestantes em sala de espera, visando à promoção da saúde e a capacitação acerca das necessidades nutricionais peculiares à gestação e a lactação.

Palavras-chave: Alimentação Saudável, Gravidez, Intervenção Nutricional, Alimentação na Gestação, Recomendações Nutricionais.

Eliane Rodrigues de Faria Sâmila Marques Muniz Nadine Piller Albino Marques Isabela Afonso Pereira Maria Carolina Reis Rente Laise de Carvalho Neves Glauciana Azarias de Paiva

eliane.faria@ufjf.edu.br

Universidade Federal de Juiz de Fora (UFJF) 
Abstract

The precepts of a healthy diet are essential to large demands of nutritional pregnancy and events related to it, such as lactation. Thus, it is clear that the empowerment of women on a balanced diet rich in nutrients is necessary, since nutrition is one of the most important pillars for the health of the mother-child binomial. Thus the objective of this study was to carry out educational strategies with participants from the pregnant and expectant mothers group in the waiting room, aiming at promoting health and training about the nutritional needs peculiar to gestation and lactation.

Keywords: Healthy Diet, Pregnancy, Nutritional Intervention, Pregnancy Supply, Recommended Dietary Allowances. 


\section{INTRODUÇÃO}

A gestação é um processo que acarreta uma série de transformações no organismo da mulher, as quais são necessárias para regular o metabolismo materno, promover o crescimento e desenvolvimento fetal e preparar a mãe para o trabalho de parto, nascimento e lactação. Além disso, a gravidez é um período de intensas adaptações físicas e emocionais. Nesse período, um misto de emoções, ansiedade e dúvidas são bastante comuns, e a alimentação é um dos pontos que merece atenção especial, já que esta é fonte de muitas incertezas (Baião, Deslandes, 2006; Dametto, 2007).

Gestantes representam um grupo com muitas particularidades na composição de sua dieta, pois nesse momento há uma maior necessidade de todos os nutrientes básicos. Em decorrência das novas demandas nutricionais, o estado anabólico é dinâmico, constante e promove ajustes contínuos em relação a diversos nutrientes. Com isso, o estado nutricional favorável, além de prevenir as carências nutricionais, garante todos os nutrientes necessários para a evolução adequada da gestação e do feto, já que sua única fonte de nutrientes é constituída pelas reservas nutricionais e pela ingestão alimentar da mãe, o que justifica a importância do estado nutricional materno durante a gestação. Também assegura as reservas biológicas necessárias ao parto, ao pós-parto e à lactação, sendo este um processo que envolve interação profunda entre mãe e filho, com repercussões no estado nutricional da criança, capacidade de defender contra infecções, em sua fisiologia e no seu desenvolvimento cognitivo e emocional, além de ter implicações na saúde física e psíquica da mãe (Klein, Guedes, 2008; Santos, Borges et al., 2017).

O estado nutricional antes e durante a gravidez é um fator determinante para a saúde da gestante e seu concepto, no entanto, observa-se que muitas gestantes apresentam conhecimento limitado acerca de assuntos relacionados às necessidades nutricionais na gestação e lactação. Dessa forma, torna-se relevante a realização de atividades educativas que proporcionem o empoderamento das gestantes sobre uma alimentação saudável e com nutrientes variados.

No Brasil, são descritos dois conceitos de empoderamento. O primeiro refere-se a mobilizações e desenvolvimentos de práticas e/ou projetos que tenham como objetivo motivar grupos ou comunidades na melhora de suas condições de vida e autonomia em suas escolhas. O outro sentido está relacionado às ações que promovam a integração dos menos favorecidos em serviços importantes para sua sobrevivência como saúde, educação, medicamentos, lazer e etc (Kleba, Wendausen, 2009; Gohn, 2004).

Sendo assim, ressalta-se a importância desse conceito de empoderamento para entendimento deste trabalho que foi desenvolvido com o intuito de tratar da promoção à saúde. Sabe-se que o processo de empoderar é um método utilizado para promover saúde, e o empoderamento de um indivíduo ou coletividades os torna aptos a mudarem seu estilo de vida, escolhas e consequentemente a sua saúde (Romanini, 2014). 
Promoção à saúde de acordo com Ministério da saúde (2002) relaciona-se com a criação de espaços saudáveis para melhoria da qualidade de vida do indivíduo e coletividades, bem como desenvolver ações que visem à saúde antes que a doença já tenha se instalado e oferecer atenção ao indivíduo como um todo, respeitando seu estilo de vida, hábitos, cultura, religião e etc. Promover saúde é compartilhar saberes para construção de estratégias de cuidado em saúde.

O empoderamento aplicado à promoção da saúde baseia-se, portanto, em um processo no qual o indivíduo ganha maior controle em suas decisões e ações, podendo melhorar seu estilo e qualidade vida (MINISTÉRIO DA SAÚDE, 2002; CarvaIho, 2012). Desta forma, o objetivo do projeto foi realizar estratégias educativas com participantes do grupo de gestantes e gestantes em sala de espera em um hospital da cidade de Juiz de Fora, Minas Gerais, visando à promoção à saúde e a capacitação acerca das necessidades nutricionais peculiares à gestação e a lactação.

\section{METODOLOGIA}

O presente trabalho se refere ao relato de experiência acerca de uma atividade de extensão, desenvolvida no período de um ano (julho/2016 a julho/2017), envolvendo docente e discentes do Curso de Nutrição da Universidade Federal de Juiz de Fora. As atividades eram desenvolvidas por meio de encontros com grupo de gestantes, realizadas nas dependências de um hospital público da zona sul da cidade de Juiz de Fora. Tais ações tinham como objetivo criar um espaço para promoção de educação em saúde voltada para a alimentação do público alvo, visto que tanto o curso ministrado anteriormente, quanto às atividades desenvolvidas nas salas de espera, não tinham enfoque em nutrição materno-infantil.

Participava do grupo uma equipe multidisciplinar composta pelas áreas de Medicina, Fisioterapia, Enfermagem, Educação Física, e recentemente a Nutrição, em conjunto com as gestantes e seus acompanhantes. Esses encontros aconteciam às terceiras sextas-feiras de cada mês, onde eram abordados temas gerais relacionados à gestação e lactação. O curso caracterizava-se por ser um espaço onde se desenvolviam atitudes e comunicavam-se conhecimentos, constituindo-se uma estratégia para melhorar a qualidade de vida dessas pessoas através de um empoderamento acerca dos assuntos abordados.

Já as intervenções de salas de espera, eram desenvolvidas no período que as gestantes e seus acompanhantes aguardavam diferentes atendimentos, sendo estes, realização de exames pré-natais, consultas de rotina, entre outros. Pelo fato dos atendimentos acontecerem por ordem de chegada, havia um impasse das gestantes não estarem disponíveis para ir ao encontro do grupo. Desse modo, a realização das atividades da sala de espera ocorria com a ida das intervencionistas até as gestantes, com os materiais a serem utilizados para auxiliar no desenvolvimento da ação e tinham duração de mais ou menos duas horas.

No total, foram realizados doze encontros, sendo que cada tema abordado foi realizado três vezes, conforme o exemplo a seguir: 
- Mês 1: Alimentação Durante a Gestação.

- Mês 2: Desvendando Sabores.

- Mês 3: Banco de Leite Humano e Aleitamento Materno.

- Mês 4: Alimentos e suas Influências no Leite Materno.

No mês 5 retornava-se ao tema 1; no mês 6 , ao tema 2 e assim sucessivamente.

Por ser um serviço com muita rotatividade, não foi possível realizar todas as atividades com os mesmos grupos de gestantes, sendo assim, alguns grupos participaram somente das reuniões e outros somente das salas de espera.

Como fonte das informações, para sustentação do relato deste artigo, utilizaram-se as narrativas das atividades, sobre as quais se discorre adiante.

\section{Intervenção: Alimentação durante a gestação}

A intervenção, desenvolvida no curso, abordou o tema "Alimentação durante a gestação" com o objetivo de explicar a importância de uma alimentação saudável, principalmente nesse período gestacional, salientando os alimentos benéficos e maléficos.

De forma lúdica e interativa, réplicas de alimentos saudáveis e não saudáveis, foram inseridas em uma caixa lacrada, com o intuito de impossibilitar a escolha destes pelas participantes. Uma intervencionista ficou responsável por levar a caixa até as gestantes, e as mesmas retiravam uma réplica aleatoriamente. Feito isso, outra intervencionista questionava sobre o que as participantes entendiam sobre alimentos saudáveis e não saudáveis. Através deste questionamento foi solicitado que as participantes que estivessem com alimentos considerados saudáveis levantassem as réplicas distribuídas previamente. O mesmo processo foi realizado com os alimentos considerados não saudáveis.

De acordo com os relatos de opinião das gestantes, foram sanadas as dúvidas que surgiram ao longo da dinâmica.Um relato especial que chamou a atenção das organizadores foi o questionamento sobre a salsicha, que num primeiro momento foi considerada um alimento saudável por algumas integrantes do grupo.Por fim, foi salientado a importância do consumo de alimentos in natura ou minimamente processados e a necessidade de evitar os processados e ultraprocessados, segundo o Guia Alimentar para População Brasileira (2014).

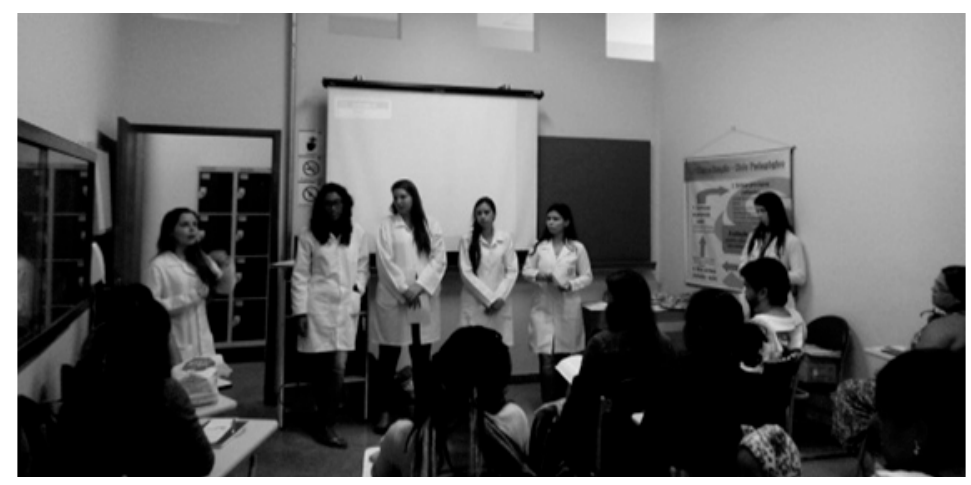


A intervenção na sala de espera abordou o tema :Desvendando sabores", tendo como objetivo avaliar os conhecimentos prévios sobre alimentos e nutrientes que são importantes para o bom desenvolvimento e crescimento do feto em cada trimestre da gestação, além daqueles que auxiliam no alívio de sintomas que surgem durante a gravidez.

As intervencionistas elaboraram previamente receitas de fácil preparo e baixo custo, que continham os nutrientes essenciais e que deveriam ser consumidos durante o período gestacional, tanto para a mãe quanto para o feto. Essas preparações foram oferecidas às gestantes que esperavam por atendimento médico, junto com material educativo contendo o passo a passo de cada receita.

As receitas foram selecionadas com a finalidade de amenizar os sintomas mais comuns nessa fase, como constipação intestinal, através da receita de Bolo de Maçã com Casca, a fim de aumentar o aporte de fibras diário. Já para a queixa sobre azia foi preparado um suco digestivo e refrescante, contendo maçã, limão e hortelã. Para aumentar a ingestão de vitaminas e minerais foi desenvolvida uma segunda opção de suco, contendo beterraba, cenoura e água de coco.

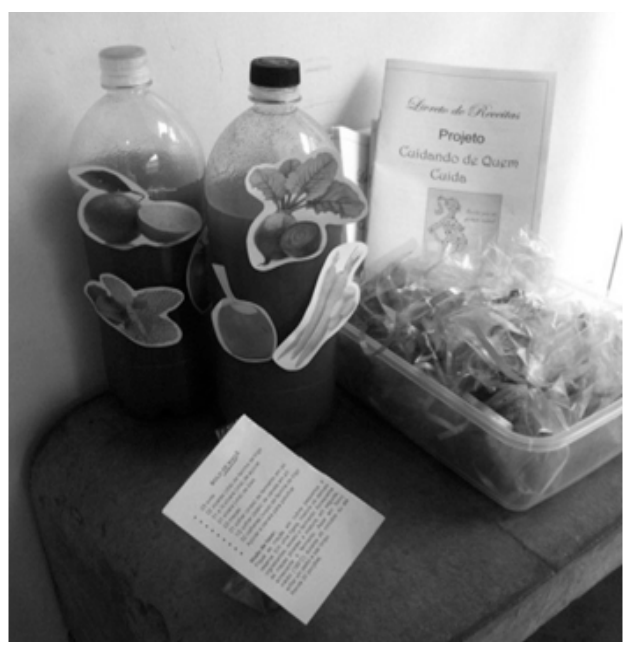

Intervenção: Banco de Leite e Aleitamento Materno

A intervenção, desenvolvida no curso, abordou o tema "Banco de Leite e Aleitamento Materno". O objetivo consistiu em desmistificar, por meio de uma dinâmica, curiosidades, mitos e verdades sobre amamentação e o leite materno.

Para a elaboração dessa atividade, as intervencionistas buscaram informações e conhecimento no banco de leite local, onde também foram disponibilizados materiais educativos para utilização no curso. Através de uma conversa informal com as participantes, os seus conhecimentos prévios sobre aleitamento materno e doação do leite humano foram discutidos. Para início da dinâmica, as intervencionistas realizaram uma palestra sobre a importância do aleitamento materno e seus 
benefícios para mãe e bebê; pega correta; diferentes tipos de mamilos; complicações comuns; ato de amamentar e doar o que for excedente; banco de leite local; postos de coleta e critérios para doação. Em seguida foi realizado um Quiz abordando mitos e verdades desse tema, onde as participantes receberam uma plaquinha, contendo os dizerem "SIM" e "NÃO" para responder perguntas sorteadas pelas mesmas. Por exemplo: "Comer canjica aumenta produção de leite?”. A medida que os participantes respondiam aos questionamentos, discutia-se com o grupo sobre o tema exposto e dúvidas eram sanadas. Por fim, foi mostrado um kit necessário para ordenha no momento da coleta. Além disso, foram entregues panfletos autoexplicativos. Ao final, foi passado um vídeo do Ministério da Saúde em incentivo ao aleitamento materno.

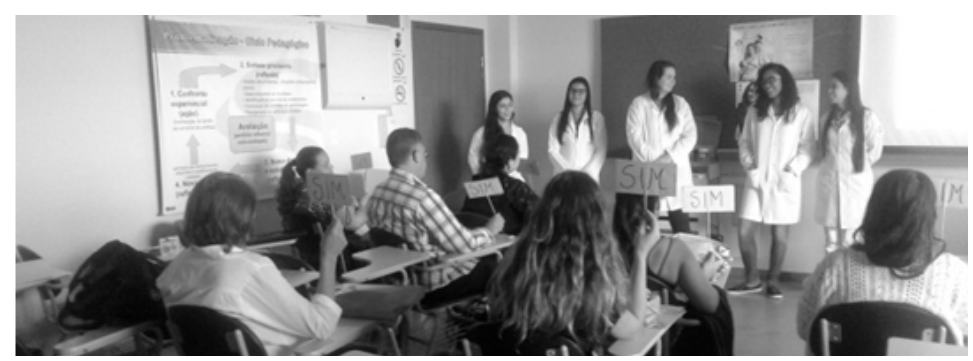

Intervenção: Alimentos e suas influências no Leite Materno

A intervenção abordou, de forma descontraída, o tema "Alimentos e suas Influências no Leite Materno", em sala de espera, e teve por objetivo avaliar o conhecimento prévio sobre os alimentos, e de que forma eles podem influenciar na qualidade do leite materno.

As estudantes se deslocaram até as gestantes que estavam na sala de espera, para orientar, por meio de uma conversa informal, sobre os alimentos que são consumidos por elas e que podem interferir na saúde do seu filho. As mesmas foram presenteadas com um livreto contendo jogos educativos, elaborados pelas organizadoras, com intuito de possibilitar o entendimento do tema de forma simplificada, explorando o entretenimento.
Figura 3: Conversa sobre aleitamento materno e dinâmica.

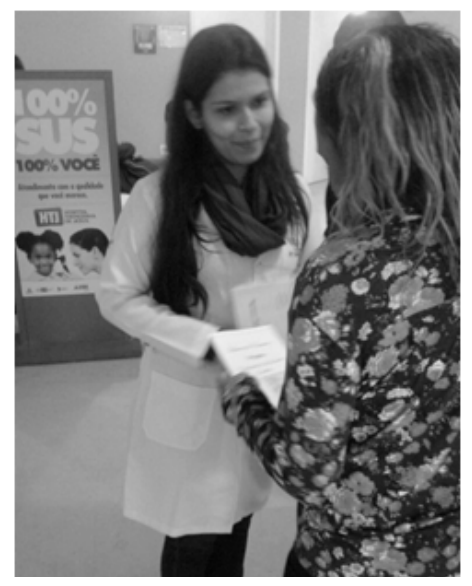


As avaliações de todas as intervenções foram realizadas através de uma pesquisa de satisfação com os participantes. No geral, foi perguntado sobre qual tinha sido a visão dos mesmos em relação ao que lhes foi apresentado, se havia alguma crítica ou sugestão a ser acrescentada e se os alimentos degustados foram bem aceitos.

\section{RESULTADOS}

As gestantes revelaram algumas fragilidades no cuidado com a alimentação, especialmente em relação à frequência e qualidade das refeições. Contudo, os objetivos do projeto, de forma geral, foram alcançados. Consideramos que foi possível promover maior interação entre o conhecimento das acadêmicas e das participantes através da metodologia utilizada. Com isso, nos aproximarmos mais da realidade das mulheres atendidas no hospital, tendo como consequência das atividades uma maior interação entre gestantes, profissionais de saúde e extensionistas, além de alcançar um bom número de mulheres, que foram beneficiadas com ações educativas de prevenção e promoção da saúde.

No que se refere ao número de gestantes durante a atuação do projeto, somam-se ao fim do período um total de, aproximadamente, 50 gestantes atendidas nos grupos e 50 nas salas de espera. As atividades realizadas nos grupos de gestantes e salas de espera foram desenvolvidas a partir de temas de abordagem referentes à alimentação durante a gestação e lactação.

Outro ponto a ser enfatizado é o impacto técnico e científico que o projeto proporcionou contribuindo para o crescimento profissional e formação das extensionistas. As estudantes tiveram a oportunidade de se inserir na extensão e pesquisa científica com foco em temas atuais, discutindo metodologias no cenário da saúde coletiva e foram beneficiadas na perspectiva da construção de um novo saber coletivo e participativo, o que permitiu uma expansão de conhecimentos com a inserção no campo prático e com a vivência de diferentes realidades.

Os resultados foram analisados por meio de uma pesquisa de satisfação quanto à metodologia aplicada durante as intervenções em relação a abordagem dos temas, abordagem adotada à partir dos instrumentos utilizados nos encontros, se o tema foi relevante para a gestante, se conseguiria aplicar no seu dia-a-dia, etc. Pelo fato de os resultados das intervenções serem semelhantes, optou-se por demonstrar os gráficos referentes à apenas uma intervenção em uma turma. Segue abaixo, os gráficos de 1 a 5 . 


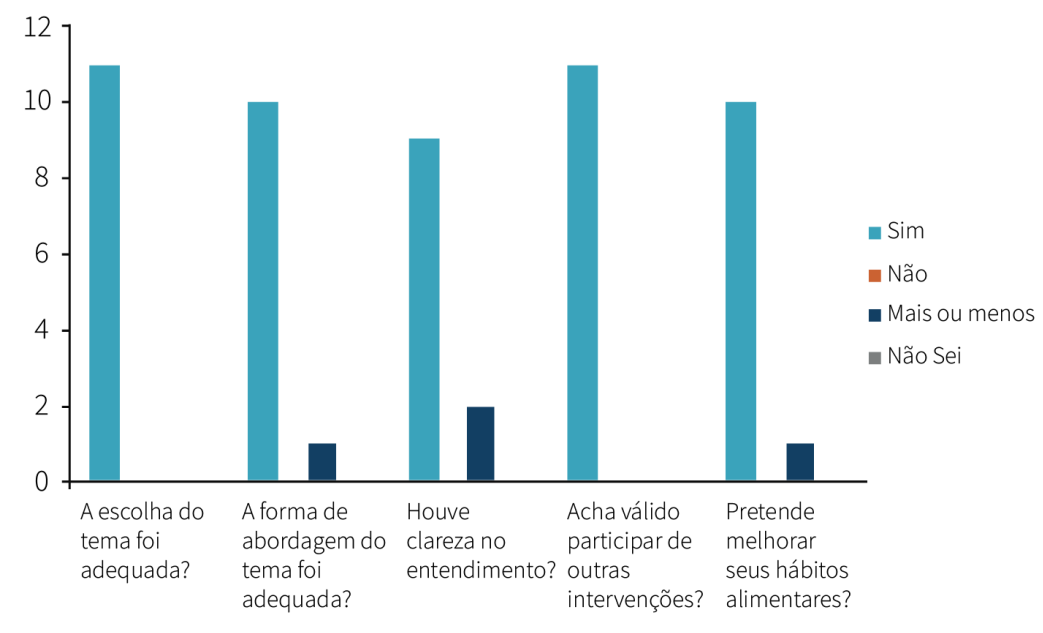

Gráfico 1: Avaliação da intervenção "Alimentação durante a gestação” em turma 1.

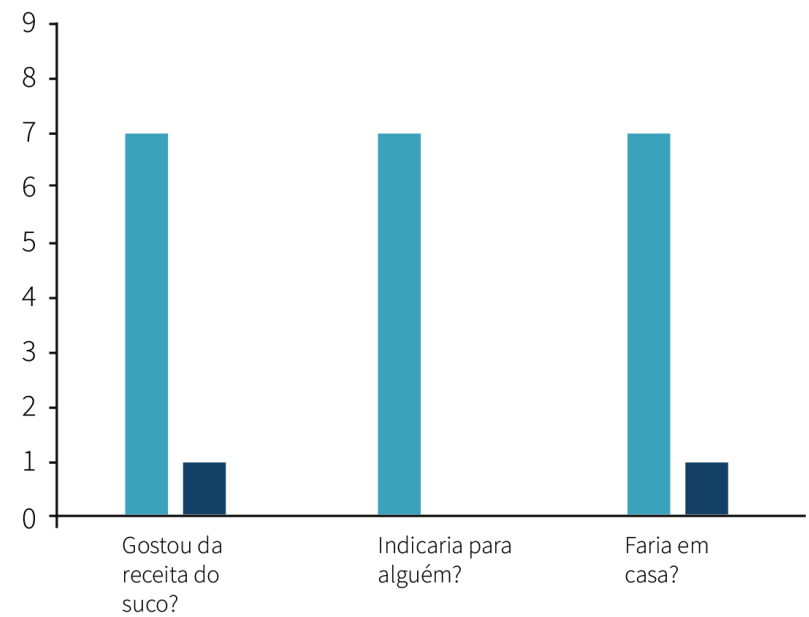

intervenção "Desvendando sabores" em turma 1.

$$
\begin{aligned}
& \text { Sim } \\
& \text { Não }
\end{aligned}
$$

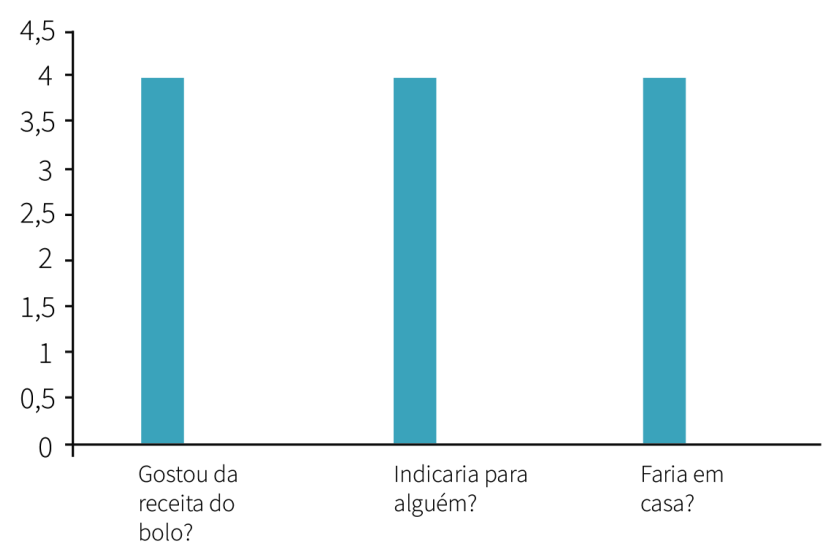

Gráfico 3: Avaliação da intervenção "Desvendando sabores” em turma 1. 
Gráfico 4: Avaliação da intervenção "Banco de Leite e Aleitamento Materno" em turma 1.

Gráfico 5: Avaliação da intervenção "Alimentos e suas influências no Leite Materno" em turma 1.
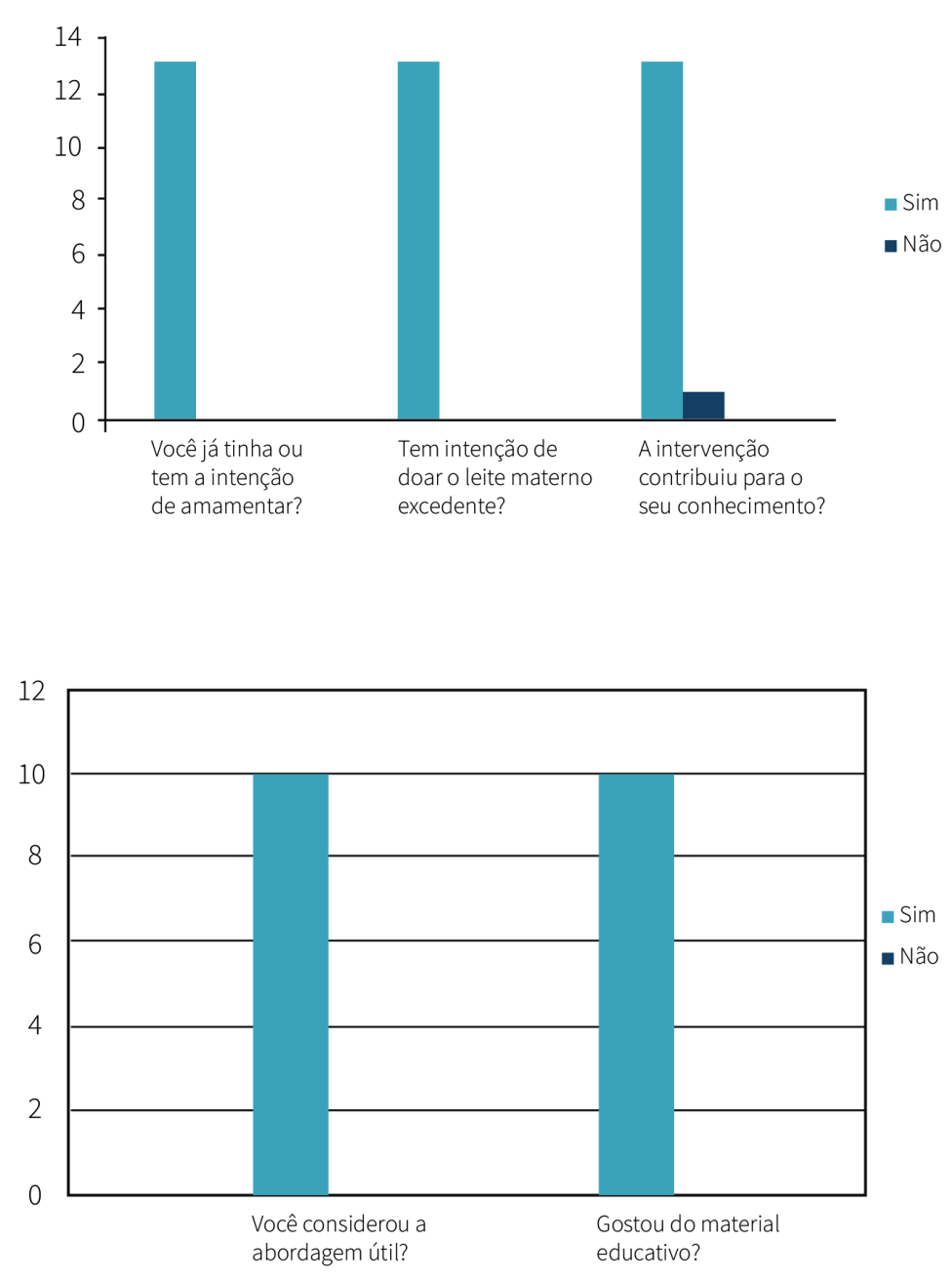

\section{DISCUSSÃO E CONCLUSÃO}

Durante o processo de construção das ações de educação alimentar e nutricional, foi possível notar que os temas abordados nos encontros com as gestantes eram de relevante importância, pois suscitaram dúvidas e interesse por parte do público presente, que participaram das dinâmicas e discussões, podendo então perceber como um fator positivo a adesão das gestantes e seus acompanhantes à proposta do projeto.

Dessa forma, as atividades desenvolvidas ao longo dos meses mostraram-se importante para a promoção da saúde das gestantes, como nos estudos realizados por Laporte-Pinfildi e Medeiros (2016); Neves, Mendes et al (2015), que defenderam a necessidade de práticas educativas nutricionais como influência benéfica durante o período gestacional e puerpério. 
Os resultados obtidos nos gráficos que foram utilizados como métodos de avaliação aplicados ao final de cada encontro apresentaram resposta positiva em relação aos temas abordados, evidenciados por mais de 50\% dos participantes durante a avaliação, que se mostraram dispostas a mudar, melhorar ou até mesmo incluir novos hábitos e cuidados que possam influenciar de maneira positiva durante a gestação. Todavia, como em estudos realizados por Laporte-Pinfildi e Medeiros (2016); Neves Oliveira, Gomes et al (2010), e através da observação feita neste período, foi possível perceber que crenças e mitos com a alimentação são ainda bem presentes no cotidiano das participantes, tornando necessário intervenções educativas cada vez mais rotineiras, com o objetivo de sanar e desmistificar conteúdos não comprovados cientificamente e que influenciam de modo negativo o cuidado da mãe e do filho, como por exemplo a pergunta: "Comer canjica doce aumenta o leite?"

Entretanto, o projeto extensionista proporcionou às acadêmicas a oportunidade de levar e adquirir conhecimentos culturais e técnicos, resultando em um momento de aprendizado e de descontração, bem como uma troca de saberes e experiências entre o público participante e as acadêmicas do curso de nutrição, conforme visto por Almeida e Lacerda (2 012) em que extensionistas criaram o grupo de gestantes com o mesmo objetivo.

Concluímos assim que, a partir destas ações, a atenção humanizada e com qualidade influenciou positivamente no processo da gestação e lactação, acarretando vantagens à saúde do binômio mãe-filho. Nesse sentido, este projeto realizado por equipe multiprofissional auxilia na melhora do nível de conhecimento, na mudança de hábitos alimentares, e consequentemente, na qualidade de vida destas gestantes.

\section{REFERÊNCIAS}

Almeida, A. B.; LACERDA, D. A. L. Extensão universitária na formação de um grupo de gestantes. Rev. Ciênc. Ext. v.8, n.1, p.152-160, 2012.

Baião, M, R.; Deslandes, S, F. Alimentação na gestação e puerpério. Curitiba: Revista de Nutrição, 2006. Disponível em: <http://www.scielo.br/scielo.php?script=sci_arttext\&pid=S1415-52732006000200011>. Acesso em: 06 jul. 2016. BRASIL, MINISTÉRIO DA SAÚDE. Política Nacional de Promoção da Saúde, 2002.

Carvalho, L, F. Empowerment: uma alternativa em promoção de saúde. Monografia (Especialização) - Curso de Especialização em Atenção Básica em Saúde da Família, Universidade Federal de Minas Gerais. Conselheiro Lafaiete, 2012. Disponível em:<https://ares.unasus.gov.br/acervo/handle/ARES/4944>. Acesso em: 30 de set. 2018.

Dametto, J. F. S. Avaliação antropométrica e alimentar de gestantes atendidas pelo programa de saúde da família (PSF) no município de Araraquara - SP. 2007. 80 f. Monografia (Especialização) - Curso de Nutrição, Universidade Estadual Paulista "júlio de Mesquita Filho", Araraquara - Sp, 2007.

Débora, O, R et al.Crenças alimentares no aleitamento materno. Um estudo entre gestantes e nutrizes atendidas em uma maternidade pública no município de São Paulo. Arquivos Brasileiros de Ciências da Saúde, v. 36, n.2, p.67-71, mai/ago. 2011

Delmontes, T,S et al. Relato de experiências em educação alimentar e nutricional com gestantes de uma unidade básica de saúde da cidade de Jardim - CE. In: VI SEMANA DE INICIAÇÃO CIENTíFICA DA FACULDADE DE JUAZEIRO 
DO NORTE, 6., Juazeiro do Norte. Semana de Iniciação Científica.

Frigo, L, F et al. A importância dos grupos de gestante na atenção primária: um relato de experiência. Revista de Epidemiologia e Controle de Infecção, Santa Cruz, v. 2, n. 3, p.113-114, ago. 2012.

Gohn, M. Empoderamento e participação da comunidade em políticas sociais. São Paulo: Saúde e Soc. São Paulo. v.13, n.2, p.20-31, 2004.

Ichisato, S.M.T.; Shimo, A.K.K.; Aleitamento materno e as crenças alimentares. Revista Latino-americana. Enfermagem, São Paulo, v.9, n.5, set./out. 2001.

Kleba, M, E. et al. Empoderamento: processo de fortalecimento dos sujeitos nos espaços de participação social e democratização política. São Paulo: Saúde Soc. São Paulo. v.18, n.4, p.733-743, 2009.

Klein, M, M, S.; Guedes, C, R. Intervenção psicológica a gestantes: contribuições do grupo de suporte para a promoção da saúde. Psicologia: Ciência e Profissão, Brasília, v. 28, n. 4, p.862-871, dez. 2008.

Laporte-Pinfild, A, S, C.; Medeiros, M, A. A atenção nutricional ao pré-natal e puerpério: relato de experiência em um município do litoral Paulista. Revista Nutr., vol. 29, n.6, p.947-961, nov/dez. 2016.

Neves, A, M.; Mendes, L, C.; Silva, S, R. Práticas educativas com gestantes adolescentes visando a promoção, proteção e prevenção em saúde reme. Revista Min Enferm., v.19, n.1, p.241-244, jan/mar 2015.

Romanini, A, R, M. Empoderamento individual, empoderamento comunitário e conscientização: um ensaio teórico. Psicologia e Saber Social. v.13, n.1, p.83-95, 2014.

Santos, D, K, S et al. Estado nutricional pré-gravídico e gestacional: detecção de desvios nutricionais entre gestantes atendidas pela rede pública de saúde de Palmas - TO. Revista Desafios - v.04, n.03, 2017.

WENDAUSEN, M, E, K, A. Empoderamento: processo de fortalecimento dos sujeitos nos espaços de participação social e democratização política. São Paulo: Saúde Soc. São Paulo. v.18, n.4, p.733-743, 2009 